Louisiana State University

LSU Digital Commons

$1-1-1998$

\title{
Overt and relational aggression in Russian nursery-school-age children: parenting style and marital linkages.
}

C. H. Hart

Brigham Young University

D. A. Nelson

Brigham Young University

C. C. Robinson

Brigham Young University

S. F. Olsen

Brigham Young University

M. K. McNeilly-Choque

Brigham Young University

Follow this and additional works at: https://digitalcommons.Isu.edu/biosci_pubs

\section{Recommended Citation}

Hart, C., Nelson, D., Robinson, C., Olsen, S., \& McNeilly-Choque, M. (1998). Overt and relational aggression in Russian nursery-school-age children: parenting style and marital linkages.. Developmental psychology, 34 (4), 687-697. https://doi.org/10.1037/0012-1649.34.4.687

This Article is brought to you for free and open access by the Department of Biological Sciences at LSU Digital Commons. It has been accepted for inclusion in Faculty Publications by an authorized administrator of LSU Digital Commons. For more information, please contact ir@lsu.edu. 


\title{
Overt and Relational Aggression in Russian Nursery-School-Age Children: Parenting Style and Marital Linkages
}

\author{
Craig H. Hart \\ Brigham Young University - Provo, craig_hart@byu.edu \\ David A. Nelson \\ University of Minnesota \\ Clyde C. Robinson \\ Brigham Young University - Provo \\ Susanne Frost Olson \\ Brigham Young University - Provo \\ Mary Kay McNeilly-Choque \\ Brigham Young University - Provo
}

Follow this and additional works at: https://scholarsarchive.byu.edu/facpub

Part of the Other Social and Behavioral Sciences Commons

\section{BYU ScholarsArchive Citation}

Hart, Craig H.; Nelson, David A.; Robinson, Clyde C.; Olson, Susanne Frost; and McNeilly-Choque, Mary Kay, "Overt and Relational Aggression in Russian Nursery-School-Age Children: Parenting Style and Marital Linkages" (1998). Faculty Publications. 4134.

https://scholarsarchive.byu.edu/facpub/4134

This Peer-Reviewed Article is brought to you for free and open access by BYU ScholarsArchive. It has been accepted for inclusion in Faculty Publications by an authorized administrator of BYU ScholarsArchive. For more information, please contact scholarsarchive@byu.edu, ellen_amatangelo@byu.edu. 


\title{
Overt and Relational Aggression in Russian Nursery-School-Age Children: Parenting Style and Marital Linkages
}

\author{
Craig H. Hart \\ Brigham Young University \\ David A. Nelson \\ University of Minnesota \\ Clyde C. Robinson, Susanne Frost Olsen, and Mary Kay McNeilly-Choque \\ Brigham Young University
}

\begin{abstract}
Maternal and paternal parenting styles and marital interactions linked to childhood aggressive behavior as described in Western psychological literature were measured in an ethnic Russian sample of 207 families of nursery-school-age children. Results corroborated and extended findings from Western samples. Maternal and paternal coercion, lack of responsiveness, and psychological control (for mothers only) were significantly correlated with children's overt aggression with peers. Less responsiveness (for mothers and fathers) and maternal coercion positively correlated with relational aggression. Some of these associations differed for boys versus girls. Marital conflict was also linked to more overt and relational aggression for boys. When entered into the same statistical model, more marital conflict (for boys only), more maternal coercion, and less paternal responsiveness were found to be the most important contributors to overt and relational aggression in younger Russian children.
\end{abstract}

Children's aggression in the peer group and its relationship to parenting styles and patterns of marital and family interaction has a relatively long tradition of empirical inquiry in Western psychological literature (see Hart, Olsen, Robinson, \& Mandleco, 1997, for a review ). Recently, efforts to link maladaptive behaviors to a host of social-psychological outcomes in preschool-age and older children have focused on overt and relational forms of aggression (e.g., Crick, Casas, \& Mosher, 1997; McNeilly-Choque, Hart, Robinson, Nelson, \& Olsen, 1996). However, exploring ways that different forms of aggression are associated with family processes is a relatively new area of inquiry (Crick et al., in press). Although there is significant knowledge concerning linkages between family processes and overt forms of aggression (e.g., Crick \& Dodge, 1994), little

Craig H. Hart, Clyde C. Robinson, Susanne Frost Olsen, and Mary Kay McNeilly-Choque, Department of Family Sciences, Brigham Young University; David A. Nelson, Institute of Child Development, Lniversity of Minnesota.

Portions of this research were presented at the International Society for the Study of Behavioral Development Meetings in Quebec City, Qucbec, Canada, August 1996. We express appreciation to Nina Bazarskaya, Head of the Foreign Language Department; Voronezh Forestry Institute, Voronezh, Russia; and Trevor McKee, President of International Language Programs and Associate Professor, Department of Family Sciences, Brigham Young University for their assistance in providing access to this sample. Gratilude is also extended to the Kennedy Center for International Studies for primary grant support and to the College of Family, Home, and Social Sciences, the Camilla Eyring Kimball Endowment, and the Center for Studies of the Family at Brigham Young University for additional support of this work. Joseph Olsen of Brigham Young University is also gratefully acknowledged for his statistical consultation.

Correspondence concerning this article should be addressed to Craig H. Hart, Department of Family Sciences, Brigham Young University, Provo, Utah 84602 . Electronic mail may be sent to craig_hart@ byu.edu. is known about how relational aggression develops in the context of the family. Moreover, cross-cultural insights into possible antecedents of aggressive childhood behavior are few, with the majority of studies being conducted in North America.

Aggression is generally defined as behavior enacted with the intent to hurt or harm others. Using this definition, Crick and colleagues (e.g., Crick et al., in press) define relational aggression as behaviors that harm others through damage (or threat of damage) to relationships. For example, threatening to withdraw friendship to get one's own way or using social cxclusion as a form of retaliation damages another's feelings of acceptance, friendship, or group inclusion. Overt aggression harms others through damage (or the threat of damage) to another's physical or psychological well-being and includes behaviors such as pushing, hitting, intimidating, or threatening others with physical harm (Crick et al., 1997; McNeilly-Choque et al., 1996). Although relational aggression is more typical of girls and overt aggression is more characteristic of boys ( see Crick et al., in press, for a review), both boys and girls in North American samples have been found to exhibit overt and relational forms of aggression during the early childhood years (Crick et al., 1997; McNeilly-Choque et al., 1996).

The purpose of this study was to examine relationships between childhood aggressive subtypes (relational and overt) and parenting styles and marital interactions in an ethnic Russian sample. Social-emotional processes in the Russian culture have only recently been open to systematic investigation. We were particularly interested in examining whether parenting style and marital interaction linkages with overt aggression as described in the Western psychological literature could be similarly identified in contemporary Russia. The research also assessed ways that preschool-age children's relational aggression might be associated with parenting styles and marital interaction patterns in the Russian culture. 


\section{Social and Historical Context}

We first briefly describe the social and historical context that provided the setting for this investigation, particularly as related to peer group dynamics and parenting. Prior to the advent of glasnost' and perestroika in the mid- to late 1980s, traditional Soviet pedagogy promoted child-rearing methods designed to foster values supportive of citizenship in a totalitarian socialist society. These included conformity, loyalty, group-mindedness, and unquestioning acceptance of authority. Soviet educators emphasized adult authority as well as the primacy of the group as a collective and of society over the individual, thus supporting communist criticisms of individualism and the government's desire to encourage obedience to authority (e.g.. Ispa, 1994b).

The government did not consider the family to be primarily responsible for the upbringing of children. Rather, a collectivecentered system of child rearing was developed, in which families were considered to be an organic part of Soviet society (Maddock, Hogan, Antonov, \& Matskovsky, 1994). In contrast to Western ideology, in which, traditionally, parents have been assumed to play a decisive role as the agents of socialization, in the former Soviet Union, persons or groups outside the family were viewed as having primary roles in the collective upbringing of children. Parents were considered important but secondary in this process. In the socialization process, "the children's collective became an agent of adult society and the major source of reward and punishment" (Bronfenbrenner, 1970, p. 50). For children, punishment by the collective typically took the form of group sanctions, which included public criticism and the threat of exclusion from group membership.

The centralized government was capable of maintaining uniformity in child rearing instructions and attempted to do so throughout the Communist era. Philosophies endorsed by the Central Ministry of Education were passed on through childcare personnel and other sources (e.g., medical practitioners, media) to parents (Ispa, 1994b). As a result, Soviet parents were, for the most part, exposed to little diversity in child rearing opinion from government sources (Ispa, 1995). As far as specific parental child rearing ideology is concerned, Ispa (1995) noted that corporal punishment by parents was discouraged by the Soviet government for many decades as a means of fostering conformity to Soviet values (cf. Makarenko, 1937). The extant data reveal that punitive parenting (i.e., spanking) is viewed by Russian parents as being uniformly negative, although it does occur in Russian homes (Ispa, 1995). From the writings of Makarenko, a highly influential Soviet pedagogue, to more recent writers (e.g., Azarov, 1983), parents were admonished (and typically observed) to be responsive, warm, and nurturing (withdrawing such only in instances of child disobedience), to use reasoning and persuasion, and not to use authoritarian control (cf. Bronfenbrenner, 1970).

In line with traditions persisting from czarist Russia, this advice contrasted with the cultivation of emotional distance, sternness, structure, and restrictiveness that existed in school settings during much of the Soviet era that mirrored the authoritarianism of the larger culture. During the $1970 \mathrm{~s}$ and $1980 \mathrm{~s}$, however, philosophical shifts on school curriculum matters were noted (Ispa, 1994a). By the early 1990s, the dominant theme in Soviet-Russian pedagogical writing about both education and parenting appeared to favor democratic, nurturant, child rearing strategies to promote more independent thinking and autonomous behavior in children (e.g., Ispa, 1994a, 1994b).

Despite uniform societal admonitions over many decades about parenting, David Nelson of this article (who lived with a Russian family in 1992) anecdotally noted considerable diversity in parenting styles among Russian families. This diversity was corroborated in informal interviews with educators, parents, and grandparents by Clyde C. Robinson and Craig H. Hart during independent visits to Russia in 1993 and 1995 (cf. Ispa, 1995).

Although this brief historical overview is admittedly oversimplified, given the multiplicity of ethnic group and other cultural factors that comprised the former Soviet Union (Maddock et al., 1994), it does provide a starting point for this investigation, which focuses on a sample from the ethnic Russian culture. According to Maddock et al., unlike the information on parenting, the majority of literature providing glimpses into marital aspects of family life is more recent. Historically, however, there is some indication that marital hostility displayed in front of children was strongly discouraged (Makarenko, 1937).

\section{Russian Parenting Styles and Children's Aggression}

A primary aim of our study was to investigate whether Russian parenting styles might be linked to childhood aggression in ways similar to that found in the Western psychological literature (see Hart et al., 1997, for a review). Parenting styles measured in this study should not be confused with parenting practices. Practices are strategies undertaken by parents to achieve specific academic, athletic, or social competence goals in specific contexts and situations (e.g., Darling \& Steinberg, 1993; Grusec \& Goodnow, 1994; Hart, Yang, et al., in press). Styles are currently defined in the Western literature as "aggregates or constellations of behaviors that describe parent-child interactions over a wide range of situations and that are presumed to create a pervasive interactional climate" (Mize \& Pettit, 1997 , p. 291).

Darling and Steinberg (1993) postulated that parenting styles may be "equally effective in socializing children across all cultural contexts, but that the goals toward which children are socialized, and thus parenting practices, vary across these very same ecologies" (p. 494). This contrast between general parenting styles and specific parenting practices parallels the eticemic (culture-general/culture-specific) distinction found in cross-cultural research (e.g., Berry, 1989). Therefore, assuming stylistic dimensions of parenting have similar influences across cultures (see Hart, Nelson, et al., in press; Hart, Yang, et al., in press), we anticipated that our sclected parenting stylistic dimensions would be related to childhood aggression in the Russian culture.

Broad conceptualizations of authoritarian and authoritative parenting styles noted in the Western psychological literature (c.g., Baumrind, 1996) may comprise a number of separate dimensions (Barber, 1996; Darling \& Steinberg, 1993). In accordance with this perspective, the current investigation focused on one positive and two negative parenting stylistic dimensions documented in the Russian culture (e.g., Azarov, 1983; Bronfenbrenner, 1970; Ispa, 1994a, 1995). The stylistic dimensions included in this research were responsiveness, coercion, and psychological control. Each of these constructs paralleled themes 
of warmth-nurturance, authoritarian parenting, and love withdrawal that emerged in our historical overview of Russian socialization processes.

\section{Responsive Styles and Aggression}

Responsive parent-child interactions have been conceptualized in a variety of ways in the Western psychological literature and include accepting, mutually contingent, nurturant, patient, playful, sensitive, supportive, and warm parenting constructs (e.g., Chen \& Rubin, 1994; Kochanska, 1997; Russell \& Russell, 1996). Although responsiveness has been defined and measured in different ways (see Pettit \& Harrist, 1993), consistent findings have been reported. That is, mothers who are warm and responsive and who display synchronous and engaging interactions with their preschoolers have children who are more socially competent and less aggressive with peers (e.g., Harrist, Pettit, Dodge, \& Bates, 1994; Mize \& Pettit, 1997). Similar effects have been found for fathers and for mothers (Kahen, Katz, \& Gottman, 1994).

Research by Parke and colleagues (Parke, Burks, Carson, Neville, \& Boyum, 1994) has further suggested that boys who are more sociable, less abrasive, and less verbally aggressive in peer play have fathers who are more physically playful and mothers who actively engage them in play (MacDonald \& Parke, 1984). Heightened aggression and diminished prosocial behavior in preschoolers has also been linked to less responsive and more negalive affect displays during physical play on the part of fathers but not mothers (Carson \& Parke, 1996). Together, these findings suggest that a responsive and engaging parenting style facilitates sociable behavior with peers and, in accordance with expectations in this study, diminishes aggressive and aversive behavior.

Recent work has demonstrated the usefulness of exploring the unique contributions of father's and mother's parenting styles to children's social competence (Crockenberg, Jackson, \& Langrock, 1996; Hart, DeWolf, Wozniak, \& Burts, 1992). To further address this issue, we separately assessed the relations between parental responsiveness and children's aggressive peer group behavior for fathers and mothers in our Russian sample. As alluded to earlier, many dimensions of responsiveness (e.g., nurturance, playfulness, sensitivity, and warmth) have been captured in writings about Russian parenting (e.g., Bronfenbrenner, 1970; Makarenko, 1937).

\section{Coercive Styles and Aggression}

Numerous North American studies have documented linkages among parental physical and verbal coercion, children's cognitive representational processes, emotional functioning skills, and overt aggression in the peer group (see Hart et al., 1997; McFadyen-Ketchum, Bates, Dodge, \& Pettit, 1996; Parke et al., 1994 , for reviews). It is important to note that most North American studies of younger children have focused only on maternal coercion in European American samples (e.g., Dishion, Duncan, Eddy, Fagot, \& Fetrow, 1994; Hart, DeWolf, \& Burts, 1992; Pettit, Clawson, Dodge, \& Bates, 1996). However, there is some evidence for similar associations between aggressive bchavior (although not always directed toward peers) and paternal power assertion in research with younger children
(Crockenberg et al., 1996). Recent evidence that indicates that coercive parenting may not always be linked to aggression (i.e., externalizing behavior) in African American samples should also be noted, thus challenging the assumption of cultural universals (Deater-Deckard \& Dodge, 1997). As with responsiveness, another goal of this study was to assess whether there are unique associations of maternal and paternal coercion with Russian children's overt and relational aggression.

\section{Psychologically Controlling Styles and Aggression}

Recently, stylistic patterns of parenting that constrain, invalidate, or manipulate children's psychological and emotional experience and expression have been referred to as psychological control (Barber, 1996). On the basis of what Bronfenbrenner (1970) described as "love oriented" discipline, love withdrawal (e.g., avoiding child when he or she doesn't meet parental expectations) and guilt induction (e.g., telling child he or she is not as good as other children ) are two forms of psychological control that "seem to apply rather well to patterns of child rearing in the Soviet family" (p. 71). This type of parenting reflects relationally manipulative behaviors that harm others by the use of exclusionary tactics or by damaging feelings of acceptance (Crick et al., in press). Specifically, love withdrawal and guilt induction are interactional styles that parents can use to covertly manipulate the love and attachment relationship with the child by implying that love and acceptance will not be restored until the child changes his or her behavior (Barber, 1996). This type of control is different from overt behavioral coercion (e.g., physical punitiveness).

Psychologically controlling styles also contrast with a variety of other stylistic dimensions noted in the Western parenting literature (e.g., Maccoby \& Martin, 1983). Specifically, some forms of psychological intervention associated with authoritative parenting have positive implications for children (Hart, Ladd, \& Burleson, 1990). For example, although not always directly linked to less childhood aggressive behavior (cf. Hart, DeWolf, Wozniak, \& Burts, 1992; Pettit, Bates, \& Dodge, 1997), parental reasoning-oriented control has been shown to enhance sociable childhood behavior and adaptive social cognitions (e.g., Burleson, Delia, \& Applegate, 1995; Hart, DeWolf, \& Burts, 1992; 1993). As already noted, positive forms of psychological intervention reflected in responsive styles, a focus of this study, appear to enhance sociability as well as to diminish aggressive childhood behavior.

Psychological control is likely a salient construct in the Russian culture because it was the primary means of parental and peer group control encouraged during the Soviet era when more positive means of socialization failed (Bronfenbrenner, 1970). In the Western psychological literature, psychologically controlling parenting styles have been linked to overcontrolled, internalizing childhood disorders, such as anxiety and depression (e.g., Siqueland, Kendall, \& Steinberg, 1996). In accordance with the expectations for our current study, we found that parental psychological control also has been associated with behaviorally undercontrolled adolescent delinquent behaviors (Barber, 1996) and, recently, has becn linked to overt and relational aggression in school-age children (Grotpeter, 1997). However, little is known about the nature of associations involving maternal and 
paternal psychological control and aggressive subtypes in preschoolers.

\section{Marital Relationships and Children's Aggression}

Much of the research addressed to this point has focused on dyadic parent-child interactions. However, a growing body of Western literature has also explored other aspects of family interaction that are related to child peer group behavior (Hart et al., 1997). For example, past research has indicated that marital conflict, particularly overt interparental conflict to which children are exposed, is related to childhood adjustment difficulties (Cummings, 1994a; Porter \& O'Leary, 1980). Additional studics have examined children's responses to different aspects of marital conflict and have found that when marital conflict is verbally aggressive, unresolved, and includes parental disagreements over child rearing, it may emotionally upset and threaten children (Fincham, 1994). Recent theoretical writings touching on marital relationships in the former Soviet Union suggest that there may be associations between marital conflict and children's adjustment problems in the Russian culture as well (Maddock et al., 1994).

With few exceptions (see Cummings, 1994b), most research on linkages between marital conflict and child adjustment (see Fincham, Grych, \& Osborne, 1994) has focused on global categories of child maladjustment (e.g., externalizing, internalizing, distress reactions, emotional responses, and psychiatric disorders) to the exclusion of defining specific child behavior problems, such as aggression. When child aggression toward peers has been measured in marital conflict studies involving younger children (e.g., Katz \& Gottman, 1993), it is typically embedded within broader coding dimensions, such as externalizing behavior (e.g., hyperactivity, antisocial behavior, negative engagement, and lack of fairness). As noted by Fincham (1994), little is known about the ways that specific types of interparental conflict are related to specific aspects of externalizing behavior.

To cxtend this literature using our Russian sample, we sought to begin addressing these issues by focusing on two specific types of child aggression that have been defined in recent research with younger children - namely, overt and relational aggression (Crick et al., 1997; McNeilly-Choque et al., 1996). We also asked parents to identify and to rate the extent to which two forms of marital conflict were perceived to occur in front of their child. These two forms consisted of overt marital conflict (e.g., verbal hostility, quarreling, and physical abuse) and marital exclusion (e.g., avoiding, ignoring, and withdrawing affection).

\section{Parenting and Marital Linkages With Aggressive Subtypes}

Because marital conflict typically does not exist in isolation from other aspects of family interaction (e.g., Emery, Fincham, \& Cummings, 1992), a multitude of studies have explored the relationship between parenting variables and marital conflict as linked to children's adjustment (see Fincham et al., 1994; Cummings, 1994a). Some researchers have postulated that marital conflict is a background variable that only affects children through the disruption of parenting (e.g., Fauber \& Long, 1991). Alternatively, and in accordance with the approach taken in this study, Fincham et al. (1994) argued that it is productive to examine the mulual effects of parent-child relations and marital conflict as associated with childhood behavior problems. Few studies, however, have tested the unique contributions of multiple aspects of parenting and multiple aspects of marital conflict to childhood aggression in the same statistical model.

Accordingly, in our model, we examined the three different types of parenting styles as well as two different forms of marital conflict that were noted earlier and how they might mutually operate in the prediction of two specific types of childhood aggression. Because most prior research has not systematically examined maternal and paternal contributions in this regard, we also explored the unique contributions of both mother's and father's perceptions of their own parenting styles and marital conflict to childhood aggression with peers.

Our specific interest was to test a model that would aid in understanding how multiple forms of maternal and paternal parenting styles and marital conflict uniquely contribute to children's aggressive behavior. That is, children may acquire aggressive propensities through exposure to less positive maternal and paternal parenting styles that are further exacerbated by hostile patterns of marital interaction. For example, marital interaction variables may significantly contribute to childhood aggression above and beyond parenting styles. Similarly, parenting styles may make significant incremental predictions to childhood aggression, even in the context of hostile marital interactions that are also related to aggression.

In testing this exploratory model, our analysis also was designed to determine whether different forms of maternal and paternal parenting styles and marital hostility would remain significantly associated with aggression in the context of one another. Doing so would allow us to better understand which maternal and paternal parenting style variables (in combination with marital hostility or with each other) are most important for understanding children's aggressive outcomes.

Child age, gender, and parent education (as an index of Russian socioeconomic status) were controlled for in our statistical model for the following reasons. First, Crick et al. (in press) suggested that children's relational aggression may become more pronounced and sophisticated with age (relative to overt aggression). Second, as noted earlier, child gender has been found to be differentially associated with aggressive subtypes. Finally, higher levels of socioeconomic status have been associated with more relational and less overt aggression in North American preschool-age children (McNeilly-Choque et al., 1996).

\section{Method}

\section{Setting}

The setting for this investigation was Voronezh, Russia, a city of 1 million inhabitants located approximately 250 miles south of Moscow. Voronezh is considered a provincial city, with a character that is truly Russian. Until the collapse of the Soviet Union, the city was a major center of technology, production, and agriculture. Foreign visits were strictly controlled by Soviet officials, and only in 1990 did foreigners gain free access to the city. Even today, Voronezh is relatively isolated because of its southern location - detached from the political tumult of Moscow and far from the western-dominated atmosphere of St. Peters- 
burg. One significant advantage of Voronezh's isolation from foreigners is that the sample for this study was entirely composed of children and parents considered to be ethnic Russians.

\section{Sample}

Parents of 207 preschool-age children (out of a potential 255 eligible families) from 15 classrooms in three nursery schools agreed to participate ( 207 mothers and 167 fathers). The discrepancy between mother and father participation was due to 32 single-parent families and 8 fathers declining to participate. Russian nursery schools act in loco parentis, and thus we were not allowed to obtain written parental permission. However, school administrators helped arrange group meetings with the parents so that procedures of the study could be explained and questions answered. Parents were assured of confidentiality concerning individual and family data that they or teachers provided. They were also informed that they could withdraw themselves and their child from voluntary participation at any time.

On the basis of family information questionnaire responses, parent education in the sample ranged from 9 years ( 9 th grade or high school beginning) to 17 years (college education) for both mothers and fathers. Mothers averaged 14 years 11 months $(S D=2.34)$ and fathers averaged 14 years 6 months ( $S D=2.42$ ), representing a generally well-educated sample. The sample comprised 101 boys and 106 girls, with ages ranging from 3 years 7 months to 6 years 7 months $(M=5.10, S D=0.72)$ on participation during May and June of 1995. As reflected in this sample, Russian nursery-school-age children roughly correspond in age with preschoolers and kindergarteners in North America. Sixty-nine percent of the families had one child, $30 \%$ had two children, and $1 \%$ had more than two.

\section{Measurement Issues}

Before describing the measures that were used in this study, it is necessary to discuss methodological issues inherent with cross-cultural research. The primary concern is the emic-etic problem (e.g., Berry, 1989), which concerns whether behaviors under investigation are emic (arising from the culture) or etic (similar across cultures). On the basis of our reading of the Russian and Western psychological literature and our experiences with the two cultures, we have assumed (rightly or wrongly) that there is functional equivalence in the parenting style, marital conflict, and child aggression behavioral dimensions bcing studied; that is, unlike parenting "practices" mentioned earlier that may be culture specific, the behaviors explored in this investigation (e.g., parenting "styles," marital conflict) appeared to be "recurrent" within both cultural settings and to carry similar psychological meanings (cf. Berry, 1989; Darling \& Steinberg, 1993).

Assuming that we do not have "imposed etics" here, which is an imposition of theoretical concepts derived from Western culture on the Russian culture, it is appropriate to use instruments deemed to be conceptually equivalent, meaning that they should be similarly understood by individuals in both settings. One way that this was operationalized was through forward- and back-translating questionnaires to demonstrate translation equivalence. The test in this study, then, was to see if the results obtained in Russia would be metrically equivalent to similar measurements used in Western studies (e.g., Berry, 1989). Metric equivalence exists when the psychometric properties of two (or more) sets of data from two (or more) cultural groups have essentially the same coherence or structure (e.g., similarity in correlation matrices or common factor structures). Metric equivalence will be evaluated relative to work that has already been done with North American samples.

\section{Measuring Russian Parenting Styles and Marital Interactions}

Paper-and-pencil measures with demonstrated psychometric qualities in North American samples were selected, modified, or both to assess our hypotheses, as noted below. All measures were successfully forwardand back-translated by Russian linguists who were fluent in both Russian and English, with input from the investigators for difficult-to-translate items. Back-translated items were comparable with the English version. Eleven percent of the items used in this study were word-for-word translations (in the most strict sense), $65 \%$ were almost identical (e.g., word for word, but different sentence structure), and $24 \%$ were different but retained the same general meaning. For example, in the case of the latter, spanking was translated to reflect slapping because it is more typical of Russian parents to slap children (e.g., on the back of the head) rather than to spank them. Nonetheless, slapping is still a good representation of coercive, physical discipline that is culturally specific. With only minor exceptions such as this, all items were judged by two Russian linguists to be culturally appropriate. Measures used for this particular study were administered in conjunction with other measures addressing different research questions (e.g., Hart Nelson, et al., in press; Hart, Yang, et al., in press) that were distributed in three packets on three different occasions, each approximately 1 week apart.

Parenting Behavior Questionnaire. A newly derived 62-item instrument assessing parenting styles was independently completed by mothers and fathers of children attending three nursery schools. The questionnaire was developed with data from 1,251 parents of preschool- and schoolage children in the United States and demonstrated good factorial validity and internal reliability. It was designed to overcome limitations of other widely used measures for parents of young children (Robinson, Mandleco, Olsen, \& Hart, 1995). The measure is best suited for assessing constellations of parenting behaviors (styles) that create a pervasive interactional climate over a wide range of situations (Darling \& Steinberg, 1993).

Mothers and fathers rated their own behavior on a 5-point scale anchored by 1 (never) to 5 (always) for each item, while thinking about interactions with their target child (e.g., gives child reasons why rules should be obeyed; uses physical punishment as a way of disciplining). Parents also completed a set of items representing psychological control dimensions outlined by Barber (1996) that were measured in the same manner (e.g., "I am less friendly when my child doesn't see things my way"). Parenting style measures were completed by mothers and fathers in the 167 two-parent families and by mothers only in the remaining 40 families (207 total families).

On the basis of our conceptualizations that we described in the introduction, items deemed to represent Responsiveness, Coercion, and Psychological Control (i.e., love withdrawal and guilt induction) were selected from the parenting style measures. These responses were then subjected to factor analysis. A three-factor solution from combined mother and father scores was derived from a principal-axes factor analysis (eigenvalues $=4.04,2.36$, and 1.56 ), followed by varimax rotation that accounted for $45 \%$ of the variation in scores. Identical factor structures were oblained separately for mothers and fathers.

Factor loadings for the eight items constituting the Psychological Control Scale ranged from .41 to .76 , with a Cronbach's alpha of .73. Items included (a) "ceasing to talk to child until he or she pleases us again," (b) "being less friendly when child doesn't sec things our way," (c) "not looking at child when he or she disappoints us," (d) saying "If you really cared for me, you would not make me worry," (e) "telling child he or she is not as good as other children," (f) "telling child he or she is not as good as we were growing up," (g) "making child feel guilty when he or she doesn t meet expectations," and (h) "reminding child of things we have done for him or her" (Barber, 1996). The Coercion scale factor-item loads ranged from .55 to .80 , with a Cronbach's alpha of .76. The five items described (a) slapping, (b) grabbing, (c) yelling, (d) shouting at child (when he or she misbehaves or is disobedient), and (e) using physical punishment to discipline the child. The factor loadings for the tive irems that composed the Responsiveness scale ranged from .59 to .70 , with a Cronbach's alpha of .71 . Items included (a) showing patience with child, (b) being easy going and relaxed with child, (c) joking and playing with child, (d) being respon- 
sive to child's feelings or needs, and (e) giving comfort and understanding when the child is upset.

Correlations among the Psychological Control scale and Coercion scale were $.26(p<.001)$ for mothers and $.08(n s)$ for fathers. Responsiveness and Coercion were inversely correlated at $-.28(p<.001)$ for mothers and $-.44(p<.001)$ for fathers. Responsiveness and Psychological Control were not significantly correlated for mothers $(r=-.09$, $n s$ ) or for fathers $(r=-.03, n s)$. Mother's and father's psychological control, coercion, and responsiveness scores were correlated at $.38(p$ $<.001), .13(n s)$, and $.15(p<.06)$, respectively.

Marital interactions. Marital interactions were measured with a 13item Marital Hostility Scale, comprising two dimensions: Marital Conflict and Marital Exclusion. The Marital Conflict dimension was assessed with the O'Leary-Porter Scale. The eight items used included questions about how often various forms of overt marital conflict (e.g., arguing, verbal hostility, quarreling, physical abuse, criticizing, and complaining) are observed by the child. This scale has been shown to have good testretest reliability of .96 over a 2 -week period and has good concurrent validity with the Short Marital Adjustment Test (Porter \& O'Leary, 1980). The Marital Exclusion dimension was assessed by five additional items that we developed that were designed to tap into marital exclusionary tactics (e.g., avoids, ignores, gives cold shoulder, withdraws affection, and threatens divorce). Mothers and fathers independently completed the marital items by rating how often these behaviors were perceived to occur in front of their child on a 5-point scale anchored by 1 (rarely) and 5 (very often).

Two conceptually distinct and reliable factors representing maternal perceptions of marital conflict and marital exclusion were derived from a principal-components factor analysis with varimax rotation. These two factors accounted for $48 \%$ of the variation in scores (eigen values $=$ 4.5 and 1.8). Cronbach's alphas were .78 and .79 , respectively. An identical factor structure was obtained separately for fathers. The correlation between maternal and paternal perceptions of each other's exclusionary tactics was $.43(p<.001)$. Maternal and Paternal Conflict scales correlated at $.58(p<.001)$, indicating moderate levels of agreement. $\Lambda s$ would be expected for scales describing different forms of the same construct (marital hostility), Marital Conflict and Marital Exclusion scales were moderately correlated at $.42(p<.001)$ for mothers and $.48(p<.001)$ for fathers. Twenty-seven of the 167 fathers did not complete the marital hostility questionnaire. Therefore, only maternal reports of marital interaction were used in subsequent analyses to assure an adequate sample size relative to the number of predictors in our regression model.

\section{Measuring Overt and Relational Aggression.}

Relational and overt aggression items used in this study were derived from teacher measures successfully used with preschoolers in North American samples (Crick et al., 1997; McNeilly-Choque et al., 1996). ${ }^{1}$ As noted earlier, all items were forward-translated and then successfully back-translated by Russian linguists.

Teacher assessments. Teacher ratings have a number of advantages for assessing aggression over other forms of assessment for younger children (sce McNcilly-Choque et at., 1996). Accordingly, Russian teachers rated the frequency of aggressive behavior occurences for each child whose parent was participating in the study on a 3-point scale (never, sometimes, often) across items representing each of the two aggressive domains. These items were selected from those we found to best represent overt and relational aggression on the basis of pilot work with teachers who rated the behaviors of approximately $6004-5$-yearold children in the United States and subsequent findings presented in $\mathrm{McNeilly-Choque} \mathrm{et} \mathrm{al.} \mathrm{The} \mathrm{measure} \mathrm{used} \mathrm{here} \mathrm{consisted} \mathrm{of} 16$ items. Eight items assessed relational aggression (e.g.. tells a peer that he or she won't play with them if he or she doesn't do what is asked; tells other children not to play with or be a peer's (riend). The remaining 8 items assessed overt aggression. Five ilems were directed toward overt bullying behavior (e.g., threatens or intimidates other children just to be mean; enjoys picking on others), and 3 items assessed overt instrumental aggression (e.g., hits, kicks, and pushes to get something he or she wants). Six of the 16 items were derived from a pilot version of Crick et al. (1997). Teachers were provided written instructions for completing the questionnaire, and an advanced undergraduate student was available to answer questions.

A principal-components factor analysis with oblique rotation yielded two distinct factors representing Relational Aggression and Overt $\mathrm{Ag}$ gression as explained above, explaining $60 \%$ of the variation in scores. Eigenvalues were 7.7 and 2.0. Factor loadings for Relational Aggression ranged from .61 to .94 (Cronbach's $\alpha=.91$ ). Loadings for Overt Aggression ranged from .58 to .85 (Cronbach's $\alpha=.90$ ). The correlation between the two scales was moderate at .62 , which is what one would expect for constructs that are hypothesized to be different forms of the same general behavior. This correlation was almost identical to that obtained in a meta-analysis (.63) involving teacher-assessed overt and relational aggression in North American samples (Crick ot at., in press)

\section{Results}

Scores for all parenting style scales (Responsiveness, Coercion, Psychological Control), marital scales (Marital Conflict, Marital Exclusion), and child aggression scales (Overt, Relational) were derived by calculating the mean of the summed items for each scale. Correlations were then computed among all the parenting style and marital interaction scales to check for multicollinearity. This was followed by correlations between the aggression scales and the parenting style and marital interaction scores. We also analyzed the teacher measures of children's overt and relational aggression for sex differences. Finally, the model testing unique contribulions of multiple marital and parenting stylistic dimensions to aggression was tested by hierarchical regression.

\section{Correlational Analyses}

Most correlations between the three parenting style (conducted separately for mothers and fathers) and two marital hostility measures (mother perceptions only) were nonsignificant ( $r$ s ranged from .01 to .24). These and the intermeasure correlations presented earlier indicated no multicollinearity $(r \mathrm{~s}>.70)$ among the parenting and marital interaction predictors to be used in later regressions. Bivariate correlations involving Russian parenting styles and marital hostility with overt and relational aggression for boys and girls are shown in Table 1.

\section{Sex Differences in Relational and Overt Aggression}

To assess sex differences in types of aggression as perceived by Russian teachers, two sets of one-way analysis of covariance (ANCOVA) were conducted in which child gender served as the independent variable and teacher aggression scores as the dependent variables. Because prior analyses showed that relational and overt aggression were correlated for the teacher as-

\footnotetext{
${ }^{1}$ Peer behavior nominations of relational and overt aggression as well as peer sociometric data were also gathered. Peer data, a more detailed description of the teacher measure, and gender differences in Russian aggressive subtypes are reported in a separate measurement article (forthcoming).
} 
Table 1

Zero-Order Correlations Between Parenting-Marital Variables and Aggression

\begin{tabular}{|c|c|c|c|c|c|c|c|c|}
\hline $\begin{array}{l}\text { Aggression } \\
\text { type }\end{array}$ & $\begin{array}{l}\text { Cocrcion } \\
\text { (mother) }\end{array}$ & $\begin{array}{c}\text { Coercion } \\
\text { (father) }\end{array}$ & $\begin{array}{c}\text { Responsive } \\
\text { (mother) }\end{array}$ & $\begin{array}{l}\text { Responsive } \\
\text { (father) }\end{array}$ & $\begin{array}{l}\text { Psych con } \\
\text { (mother) }\end{array}$ & $\begin{array}{l}\text { Psych con } \\
\text { (father) }\end{array}$ & $\begin{array}{l}\text { Marital } \\
\text { conflict }\end{array}$ & $\begin{array}{c}\text { Marital } \\
\text { exclusion }\end{array}$ \\
\hline \multicolumn{9}{|c|}{ Boys } \\
\hline Overt & $.29 * * *$ & $.23^{*}$ & $-.23^{*}$ & $-.28 * *$ & $.28^{* * *}$ & .12 & $.26^{* * *}$ & .13 \\
\hline Relational & .17 & .15 & $-.22 *$ & $-.32 * * *$ & .12 & .02 & $.21 *$ & -.04 \\
\hline \multicolumn{9}{|c|}{ Girls } \\
\hline Overt & $.27 * * *$ & $.31 * * *$ & .05 & $-.33 * * *$ & $.22 *$ & .05 & -.03 & -.01 \\
\hline Relational & $.22^{*}$ & .20 & -.04 & -.16 & .05 & .04 & -.11 & -.06 \\
\hline
\end{tabular}

Note. Omnibus tests of the null hypothesis indicated that the correlation values of the matrix were different from zero (using Fisher's $r$ to $z$ transformation and chi-square critical evaluation; see Cohen \& Cohen, 1983 ) and occurred at a rate greater than would be expected by chance alone: boys, $x^{2}(45, N=101)=$ $148.19, p<.001$; girls, $\chi^{2}(45, N=106)=99.24, p<.001$. Psych con $=$ psychological control.

$* p<.05 . * * p<.01 . * * * p<.001$.

sessment measure, relational aggression served as the covariate for analyses of sex differences in overt aggression, and overt aggression was used as the covariate for analyses of sex differences in relational aggression (see Crick et al., 1997, for a similar procedure). Results of the two ANCOVAs indicated no significant sex effects for teacher perceptions of overt and relational aggression. Teachers perceived no significant differences for overt and relational aggression in boys versus girls $(M=$ $2.42, S D=0.38$ and $M=2.39, S D=0.38$, for overt aggression; $M=2.27, S D=0.35$ and $M=2.24, S D=0.32$, for relational aggression in boys and girls, respectively).

\section{Regression Analyses: Unique Contributions}

Regression descriptions. Two sets of hicrarchical regression analyses were performed. The first set explored whether Russian marital hostility contributed uniquely to overt and relational aggression above and beyond parenting stylistic dimensions. The second set examined whether parenting stylistic dimensions made significant incremental predictions to overt and relational aggression beyond marital hostility. These analyses also assessed whether maternal and paternal parenting stylistic dimensions and marital hostility would remain significantly associated with aggression when tested in the context of one another. Child gender, age, and parent education were entered on the first three steps of each equation to control for their possible effects.

As seen in Table 2, parenting stylistic dimensions were entered as a block on the fourth step of the first equation, with marital hostility variables entered on the fifth step. This order was reversed in the second equation, with marital hostility variables entered on the fourth step and parenting styles entered on the fifth step. Interactions of gender with each of the parenting style and marital predictors was entered on the last step of the equation. Although all interactions between gender and parenting-marital variables were tested, only significant interactions were included in the table. For interpretation, $t$ values (ratio of the coefficient to the standard error) are reported for each predictor to show which individual variables retained statistical significance when all of the predictors were taken into account on the final step of each equation. The reported betas are also from the final step of each equation.
Regression findings. Results indicated that marital hostility did not make significant incremental predictions to overt and relational aggression above and beyond parenting styles (Equation 1), although parenting styles did continue to make significant contributions to aggression after controlling for marital hostility (Equation 2). However, a significant interaction of gender with marital conflict added significantly to the prediction above and beyond parenting styles for both overt and relational aggression. Correlations involving marital conflict and aggression within each gender revealed that these relations were stronger for boys for overt $(r=.26, p<.001)$ and relational aggression $(r=.21, p<.05)$ than for girls $(r \mathrm{~s}=-.03$ and -.11 , respectively, $n s$ ). No other significant interactions involving gender added significantly to the prediction of overt or relational aggression and thus were not entered into the final model.

Results reflected in the $t$ values shown in Table 2 indicated that less paternal responsiveness and more maternal coercion retained significant relationships with both overt and relational aggression in the context of other parenting style and marital hostility variables. Other parenting style variables linked to aggression in the bivariate correlations did not (compare with Table 1). Likewise, the significant marital conflict by gender interaction persisted in the context of parenting styles and marital hostility, making significant, independent contributions to both overt and relational aggression.

\section{Discussion}

As noted in the introduction, the current study was designed not only to shed light on family interactions and children's aggression in the Russian culture but also to extend the literature in other meaningful ways. This included (a) assessing ways that multiple aspects of parenting and multiple aspects of marital conflict uniquely contribute to children's aggression in the same statistical model, and (b) using independent informants (teachers) to assess multiple forms of aggression that were measured apart from the global indexes of child externalizing and maladjustment that characterize the marital conflict literature. We also built on prior work in the parenting and marital conflict literature by incorporating both maternal and paternal perceptions and by 
Table 2

Hierarchical Regressions Performed on Overt and Relational Aggression Criteria: Parenting Style and Marital Hostility Predictors

\begin{tabular}{|c|c|c|c|c|c|c|c|c|c|}
\hline \multirow[b]{3}{*}{ Step } & \multirow[b]{3}{*}{ Variable } & \multicolumn{8}{|c|}{ Criterion } \\
\hline & & \multicolumn{4}{|c|}{ Overt aggression } & \multicolumn{4}{|c|}{ Relational aggression } \\
\hline & & $R^{2}$ & $R^{2}$ inc & $\beta$ & $t$ & $R^{2}$ & $R^{2}$ inc & $\beta$ & $t$ \\
\hline \multicolumn{10}{|c|}{ Equation 1} \\
\hline 1. & Sex & .00 & .00 & $.56^{*}$ & $2.13^{*}$ & .01 & .00 & .50 & 1.77 \\
\hline 2. & Age & .01 & .01 & -.09 & -1.25 & .03 & $.02 *$ & $.17^{*}$ & $2.14 *$ \\
\hline \multirow[t]{3}{*}{3.} & Education & .00 & .00 & & & .03 & .00 & & \\
\hline & Father & & & .04 & .45 & & & .04 & .40 \\
\hline & Mother & & & -.06 & -.67 & & & -.05 & -.49 \\
\hline \multirow[t]{8}{*}{4.} & $\begin{array}{l}\text { Parenting } \\
\text { Mother }\end{array}$ & $.22 * * *$ & $.21 * * *$ & & & $.13^{* *}$ & $.10^{* * *}$ & & \\
\hline & Psych control & & & $.16 \dagger$ & $1.86 \dagger$ & & & .01 & .05 \\
\hline & Responsive & & & .01 & .10 & & & .04 & .51 \\
\hline & Coercion & & & $.23^{* * *}$ & $2.89 * * *$ & & & $.20^{*}$ & $2.45 *$ \\
\hline & Father & & & & & & & & \\
\hline & Psych control & & & $\cdots .04$ & $\cdots .51$ & & & .01 & .12 \\
\hline & Responsive & & & $-.20^{* *}$ & $-2.46 * *$ & & & $-.21 *$ & $-2.42 *$ \\
\hline & Coercion & & & $.14 \div$ & $1.81 \dagger$ & & & .05 & .62 \\
\hline \multirow[t]{3}{*}{5} & Marital hostility & $.23 * * *$ & .01 & & & $.13^{*}$ & .00 & & \\
\hline & Conflict & & & $.20 \dagger$ & $1.84 \dagger$ & & & .18 & 1.51 \\
\hline & Exclusion & & & .09 & 1.09 & & & .01 & .16 \\
\hline \multirow[t]{2}{*}{6.} & Interactions & & & & & & & & \\
\hline & Sex $\times$ MarCon & $.26 * * *$ & $.03 * *$ & $-.69 * *$ & $-2.46^{* *}$ & $.15^{* *}$ & $.02 *$ & $-.63^{*}$ & $-2.09 *$ \\
\hline \multicolumn{10}{|c|}{ Equation 2} \\
\hline 1. & Sex & .00 & .00 & & & .01 & .00 & & \\
\hline 2. & Age & .01 & .01 & & & .03 & $.02 *$ & & \\
\hline 3. & Education & .00 & .00 & & & .03 & .00 & & \\
\hline 4. & Marital hostility & .04 & $.03 \dagger$ & & & .03 & .00 & & \\
\hline 5. & Parenting & $.23 * * *$ & $.19 * * *$ & & & $.13^{* *}$ & $.10^{* *}$ & & \\
\hline 6. & Interactions & & & & & & & & \\
\hline & Sex $\times$ MarCon & $.26 * * *$ & $.03 * *$ & & & $.15^{* *}$ & $.02 *$ & & \\
\hline
\end{tabular}

Note. Standardized regression coefficients (betas) and $t$ values are identical for the full model shown in Equations 1 and 2 for each analysis. Thus, they are only presented once in Lquation 1 and are left blank in Equation 2. inc = increment; Psych $=$ psychological; MarCon $=$ marital conflict.

$* p<.05 . * * p<.01 . * * * p<.001 .+p<.07$.

including psychological control as a parenting style construct (which had not previously been linked to children's aggression in early childhood).

In accordance with our expectations, correlational findings were generally similar to those reported for overt aggression in the Western psychological literature cited earlier. Specifically, Russian mothers and fathers who reported using more coercion had sons and daughters who were rated by teachers as being more overtly aggressive with peers. More responsiveness on the part of both mothers and fathers was linked to less overt aggression for boys. However, only father's responsiveness was associated with less overt aggression for girls. Maternal, and not paternal, psychological control was significantly associated with teacher ratings of overt aggression for boys and girls.

A similar but less pervasive pattern of relationships was found for relational aggression. More responsive parenting on the part of Russian mothers and fathers was linked to less relational aggression for boys. More maternal coercion was significantly related to higher teacher relational aggression ratings for girls.
Parental use of psychological control was not associated with relational aggression for boys or girls. Finally, marital exclusion was not linked to either form of aggression. However, mirroring findings in the Western literature, more conflict in Russian marriages was significantly associated with both forms of peer group aggression for boys but not for girls (e.g., Cummings, 1994b).

On closer examination, regression findings suggest that when maternal and paternal parenting styles are entered into the same model, higher levels of maternal coercion and lack of paternal responsiveness are the two most important contributors to relational and overt aggression in Russian nursery-school-age-children. Maternal responsiveness, paternal coercion, and maternal psychological control did not retain their significant associations with aggression when tested in combination with olher predictors in the model (compare with bivariate correlations in Table 1). Marital conflict accounted for a significant proportion of variance in boys' overt and relational aggression, above and beyond the contributions associated with maternal coercion and 
paternal responsiveness. Likewise, maternal coercion and paternal responsiveness exhibited a unique and independent association with overt and relational aggression, above and beyond marital conflict.

Several theoretical frameworks, including modeling, coercion theory, and cognitive-contextual explanations could be drawn from in interpreting our findings. These are discussed by Crick et al. (in press) and explain how children might acquire overt and relational aggression, in part, from negative family interactions. However, our data do not directly address theoretical mechanisms of how aggression might be transmitted from family interactions to peer group behavior. Notwithstanding, it should be noted that results of our study are also consistent with results of Western research indicating that a stressor model may be at work (e.g., Cummings, 1994b). This literature suggests that exposure to background anger in marital conflict and in coercive and less responsive parenting styles is emotionally and physiologically arousing for children. Such exposure appears to lower thresholds for emotional regulation and stimulates angry cognitions and feelings of hostility that may be translated into more aggression toward peers (Coie \& Dodge, 1998). As further noted by Gottman and Katz (1989), cold, unresponsive, and angry parenting is related to higher levels of childhood anger and noncompliance as well as to higher levels of stressrelated hormones. These findings underscore the importance of studying the role of affect in further studies of family-peer relationships (e.g., Carson \& Parke, 1996). In future research, it would be important to gather measures of emotional arousal to ascertain how these patterns of parent - child and marital interactions may stimulate distressful affect that may be manifest in peer group behavior that is overtly aggressive, relationally aggressive, or both.

Similar to Western findings, our results also support the idea that the absence of positive parenting is as important in the development of childhood behavior problems directed toward peers as is the presence of negative parenting (e.g., Pettit \& Bates, 1989). In terms of the development of aggression, lack of Russian paternal responsiveness and more maternal coercion remained significant contributors to overt and relational aggression, regardless of which other parenting style or marital hostility variables that they were pitted against in the regressions. Although this supports prior work concerning relationships between maternal coercion and aggression that were noted earlier, it highlights the importance of paternal responsiveness that involves positive, playful, and engaging interactions in children's social development. As noted by Carson and Parke (1996), Western studies to date have reported stronger links between responsive parenting of this nature and children's peer competency for father-child rather than for mother-child dyads. Similar conclusions could be reached for Russian responsive parenting styles when looking at our correlational findings presented in Table 1.

It is interesting that only maternal (and not paternal) psychological control was found to significantly correlate with Russian preschoolers' overt aggression. However, when pitted against the effects of other predictors in our regression model, its contribution was reduced to a marginal trend. Although these findings appear to suggest that psychological control may not be as powerfully related to aggressive outcomes in young Russian chil-
Iren, firm conclusions should be reserved for future researchers using a variety of methodological approaches.

With the exception of a significant contribution of age to relational aggression, it should be noted that other predictors, including parent education, were not found to be significantly associated with overt and relational aggression (cf. McNeillyChoque et al., 1996). This may be due to parents' education being more restricted to higher levels in this Russian sample. Bivariate correlations (not reported earlier because tangential to the study) also indicated that parents' education level was not significantly associated with parenting styles $(r s<.10)$, as has been reported in other Russian research (Ispa, 1995). This could also be due to the restricted range of parents' education. Regression findings indicating that child age was positively associated with more relational aggression support the assertion by Crick et al. (in press) that the use of relational forms of aggression increases with age.

Contrary to teachers' perceptions of preschoolers' aggression in the United States (Crick ct al., 1997; McNeilly-Choque et al., 1996), Russian teachers did not perceive sex differences in relational and overt aggression. Although highly speculative, part of the reason may be cultural in nature. As noted earlier, peer group sanctions and exclusionary tactics akin to relational aggression were promoted by the collective in the former Soviet Union as a means of socialization (Bronfenbrenner, 1970). Having been reared under this system, perhaps teachers perceive such peer group behavior as normative and equally occurring for both boys and girls. Beforc any conclusions can be drawn, observations and peer assessments of children's overt and relational aggression will be needed to assess whether this is the case for children in the current generation.

As is typical for correlational designs such as the ones reported here, findings from this study do not shed much light on the direction of effects and transactional processes. The direction of effect may not always be from parent to child. For example, parents may be more likely to turn a cold shoulder toward a highly dependent child whom he or she perceives as problematic (Pettit \& Bates, 1989). There is also some empirical evidence in the Western psychological literature suggesting that parenting styles can be influenced by child antisocial behavior. Difficult child dispositions and psychobiological influences may also contribute to negative parenting styles and aversive patterns of marital interaction that are mutually escalated in systemic ways ( see Coie \& Dodge, 1998; Hart et al., 1997). As noted by Carson and Parke (1996), researchers could address these issues in future cross-cultural work by using sibling designs, in which parents and children from the same family are observed interacting with one another, or by using cross-parenting designs, in which parents and children from different families are observed interacting with one another.

Notwithstanding the limitations associated with the use of self-report data noted in the Western research literature, our findings generally support what has been found in the Western literature that is based on a multitude of methodological approaches, some of which have demonstrated cross-informant agreement. For example, observational and self-report measures of parenting have been found to be moderately related in a variety of recent North American investigations (e.g., Pettit, Clawson, Dodge, \& Bates, 1996). Our findings highlight the usefulness of carefully conceptualized questionnaire approaches 
in other cultures in which more complex methods of data collection may be more difficult.

Furthermore, the conceptual and metric equivalence obtained in this study provides some support for our assumed notion of functional equivalence that was explained earlier. In agreement with the requirements of conceptual equivalence, all measures were successfully forward- and back-translated. Metric equivalence was illustrated by the similarity of the Russian findings to Western findings (i.e., similarity in correlation matrices and conceptually derived factor structures), even though the original measures were created with North American samples. Finally, on the basis of the existing Russian parenting-family literature and our results, it appears that the issues we studied were more likely to have arisen from the culture itself than from an imposition of our conceptual and metric biases. Findings obtained in our Russian sample parallel what has been found in North America, thus lending support for what Berry (1989) refers to as "derived etics" or "cultural universals" as pertaining only to these two cultures.

Nonetheless, we recognize the possibility that theoretical concepts derived in Western cultures may not reflect some unique conditions in the Russian culture ("imposed etics"). Other inherent ways that parenting and marital relationships may or may not be linked to aggression in the Russian culture (that are not reflected in Russian literature or in Western ideology) might not have been addressed or measured. In a related vein, recent evidence has indicated that coercive parenting is not similarly related to child aggression in all cultural and ethnic groups (e.g., African Americans; Deater-Deckard \& Dodge, 1997). Although this does not appear to be the case in our Russian sample and in primarily European American samples, it does not necessarily mean that these relationships will hold true in all parts of the world or with all ethnic groups that are subsumed within larger cultural contexts. There is also evidence suggesting that the deleterious effects of coercive parenting and marital conflict on child aggression might be buffered by a warm and responsive parent-child relationship (e.g., Deater-Deckard \& Dodge, 1997; Fincham et al., 1994).

This study represents a starting point for cross-cultural comparisons in this domain; replication studies will be needed. Qualitative research methods, including open-ended interviews and observations, may prove useful in further understanding the possible "emics" of Russian parenting, family life, and psychosocial development. In conclusion, results of this investigation suggest that there may be commonalities across Western (primarily North American) and Russian cultures involving parenting and marital linkages with early childhood aggression.

\section{References}

Azarov, Y. (1983). A book about bringing up children. Moscow: Progress Publishers.

Barber, B. K. (1996). Parental psychological control: Revisiting a neglected construct. Child Development, 67, 3296-3319.

Baumrind, D. ( 1996). The discipline controversy revisited. Family Relations, 45, 405-414.

Berry, J. W. (1989). Imposed etics-emics-derived etics: The operationalization of a compelling idea. International Journal of Psychology, $24,721-735$.

Bronfenbrenner, U. (1970). Two worlds of childhood: U.S. and U.S.S.R. New York: Russell Sage Foundation.
Burleson, B. R., Delia, J. G., \& Applegate, J. L. (1995). The socialization of person-centered communication. In M. A. Fitzpatrick \& A. L. Vangelisti (Eds.), Explaining fumily interactions (pp. 34-76). Thousand Oaks, CA: Sage.

Carson, L., \& Parke, R. (1996). Reciprocal negative affect in parentchild interactions and children's peer competency. Child Development, 67, 2217-2226.

Chen, X., \& Rubin, K. H. (1994). Family conditions, parental acceptance, and social competence and aggression in Chinese children. Social Development, 3, 269-290.

Cohen, J., \& Cohen, P. (1983). Applied multiple regression/correlation analysis for the behavioral sciences. Hillsdale, NJ: Erlbaum.

Coie, J. D., \& Dodge, K. A. (1998). Aggression and antisocial behavior. In W. Damon (Series Ed.) \& N. Eisenberg (Vol. Ed.), Handbook of child psychology: Vol. 3. Social, emotional, and personality development (pp. 779-862). New York: Wiley.

Crick, N. R., Casas, J. F., \& Mosher. M. (1997). Relational and overt aggression in preschool. Developmental Psychology, 33, 579-588.

Crick, N. R., \& Dodge, K. A. (1994). A revicw and reformulation of social information-processing mechanisms in children's social adjustment. Psychological Bulletin. 115, 74-101.

Crick, N. R., Wellman, N. E., Casas, J. F., O'Brien, K. M., Nelson, D. A., Grotpeter, J. K., \& Markon, K. (in press). Childhood aggression and gender: A new look at an old problem. In D. Bernstein (Ed.), The Nebraska Symposium on Motivation. (Vol. 45). Lincoln: University of Nebraska Press.

Crockenberg, S., Jackson, S., \& Langrock, A. M. (1996). Altonomy and goal attainment: Parenting, gender, and social competence. New Directions for Child Development, 7, 41-55.

Cummings, E. M. (1994a). Children and marital conflict: The impact of family dispute and resolution. New York: Guilford.

Cummings, E. M. (1994b). Marital conflict and children's functioning. Social Development, 3, 16-36.

Darling, N., \& Steinberg, I. (1993). Parenting style as context: An integrative model. Psychological Bulletin. 113, 487-496.

Deater-Deckard, K., \& Dodge, K. A. (1997). Externalizing behavior problems and discipline revisited: Nonlinear effects and variation by culture, context, and gender. Psychological Inquiry, 8, 161-175.

Dishion, T. J., Duncan, T. E., Eddy, J. M., Fagot, B. 1., \& Fetrow, R. (1994). The world of parents and peers: Coercive exchanges and social adaption. Social Development, 3, 255-268.

Emery, R. E., Fincham, F. D., \& Cummings, E. M. (1992). Parenting in context: Systemic thinking about parental conflict and its influence on children. Journal of Consulting and Clinical Psychology, 60, 909912.

Fauber, R. L., \& Long, N. (1991). Children in context: The role of the family in child psychotherapy. Journal of Consulting and Clinical Psychology, 59, 813-820.

Fincham, F. D. (1994). Understanding the association between marital conflict and child adjustment. Journal of Family Psychology, 8, 123127.

Fincham, F. D., Grych, J. H., \& Osborne, L. N. (1994). Does marital conflict cause child maladjustment? Directions and challenges for longitudinal research. Journal of Family Psychology, 8, 128-140.

Gottman, J. M., \& Katz, L. F. (1989). Effects of marital discord on young children's peer interaction and health. Developmental Psychology, 25, 373-381.

Grotpeter, J. K. (1997). Relational aggression. overt aggression, and family relationships. Unpublished doctoral dissertation, University of Illinois at Urbana-Champaign.

Grusec, J. E., \& Goodnow, J. J. (1994). Impact of parental discipline methods on the child's internalization of values: A reconceptualization. Developmental Psychology, 30, 4-19.

Harrist, A. W., Pettit, G. S., Dodge, K. A., \& Bates, J. E. ( 1994). Dyadic synchrony in mother-child interaction: Relations with children's subsequent kindergarten adjustment. Family Relations, 43, 417- 424. 
Hart, C. H., DeWolf, M. D., \& Burts, D. C. (1992). Linkages among preschoolers' playground behavior, outcome expectations, and parental disciplinary strategies. Early Education and Development. 3, 265283.

Hart, C. H., DeWolf, M. D., \& Burts, D. C. (1993). Parental disciplinary strategies and preschoolers' play behavior in playground settings. In C. H. Hart (Ed.), Children on playgrounds: Research perspectives and applications (pp. 271-313). Albany: SUNY Press.

Hart, C. H., DeWolf, M. D., Wozniak, P., \& Burts, D. C. (1992). Maternal and paternal disciplinary styles: Relations with preschoolers' playground behavioral orientations and peer status. Child Development. 63, 879-892.

Hart, C. H., Ladd, G. W., \& Burleson, B. R. (1990). Children's expectations of the outcomes of social strategies: Relations with sociometric status and maternal disciplinary styles. Child Development, 61, 127 137.

Hart, C. H., Nelson, D. A., Robinson, C. C., Olsen, S. F., McNeillyChoque, M. K., \& McKee, T. R. (in press). Russian parenting styles and family processes: Linkages with subtypes of victimization and aggression in young children. In K. A. Kerns, J. M. Contreras, \& A. Neal-Barnett (Eds.), Family and peers: Linking two social worlds. Westport, CT: Praeger.

Hart, C. H., Olsen, S. F., Robinson, C., \& Mandleco, B. L. (1997). The development of social and communicative competence in childhood: Review and a model of personal, familial, and extra familial processes. In B. R. Burleson (Ed.), Communication yearbook (Vol. 20, pp. 305 373). Thousand Oaks, CA: Sage.

Hart, C. H., Yang, C., Nelson, D., Jin, S., \& Nelson, L. (in press). Peer contact patterns, parenting practices, and preschoolers' social competence in China, Russia, and the United States. In P. Slee \& K. Rigby (Eds.), Peer relations amongst children: Current issues and future directions. London: Routledge.

Ispa, J. M. (1994a). Child care in Russiu: In transition. Westport, CT: Greenwood Press.

Ispa, J. M. (1994b). Child rearing ideas and feelings of Russian and American mothers and early childhood teachers. Advances in Early Education and Day Care, 6, 235-257.

Ispa, J. M. (1995). Ideas about infant and toddler care among Russian child care teachers, mothers, and university students. Early Childhood Research Quarterly, 10, 359-379.

Kahen, V., Katz, L. F., \& Gottman, J. M. (1994). The world of parents and peers: Coercive exchanges and children's social adaptation. Social Development, 3, 238-254.

Katz, L. F., \& Gottman, J. M. (1993). Patterns of marital conflict predict children's internalizing and externalizing behaviors. Developmental Psychology, 29, 940-950.

Kochanska, G. (1997). Mutually responsive orientation between mothers and their young children: Implications for early socialization. Child Development, 68, 94-112.

Maccoby, E. E., \& Martin, J. A. (1983). Socialization in the context of the family: Parent-child interaction. In P. H. Mussen (Scries Ed.) \& E. M. Hetherington (Vol. Ed.), Handbook of child psychology: Vol. 4. Socialization, personality and social development (pp. 1-102). New York: Wiley.
MacDonald, K., \& Parke, R. D. (1984). Bridging the gap: Parent-child play interaction and peer interactive competence. Child Development, $55,1265-1277$.

Maddock, J. W., Hogan, M. J., Antonov, A. I., \& Matskovsky, M. S. (1994). Families before and after Perestroika: Russian and U.S. perspectives. New York: Guilford Press.

Makarenko, A. S. (1937). The collective family: A handbook for Russian parents. (R. Daglish, Trans.). New York: Anchor Books.

McFadyen-Ketchum, S. A., Bates, J. E., Dodge, K. A., \& Pettit, G. S. (1996). Patterns of change in early childhood aggressive-disruptive behavior: Gender differences in predictions from early coercive and affectionate mother-child interactions. Child Development, 67, 24172433.

McNeilly-Choque, M. K., Hart, C. H., Robinson, C. C., Nelson, L. J., \& Olsen, S.F. (1996). Overt and relational aggression on the playground: Correspondence among different informants. Journal of Research in Childhood Education, 11, 47-67.

Mize, J., \& Pettit, G. S. (1997). Mothers' social coaching, mother-child relationship style, and children's peer competence: Is the medium the message? Child Development, 68, 291-311.

Parke, R. D., Burks, V. M., Carson, J. L., Neville, B., \& Boyum, L. A. (1994). Family-peer relationships: A tripartite model. In R. D. Parke \& S. Kellan (Eds.), Exploring family relationships with other social contexts (pp. 115-145). Hillsdale, NJ: Erlbaum.

Pettit, G.S., \& Bates, J.E. (1989). Family interaction patterns and children's behavior problems from infancy to 4 years. Developmental Psychology, 25, 413-420.

Pettit, G. S., Bates, J. E., \& Dodge, K. A. (1997). Supportive parenting, ecological context, and children's adjustment: A seven-year study. Child Development, 68, 908-923.

Pettit, G. S., Clawson, M. A., Dodge, K. A., \& Bates, J. E. (1996). Stability and change in peer-rejected status: The role of child behavior, parenting, and family ecology. Merrill-Paimer Quarterly, 42, 267294.

Pettit, G. S., \& Harrist, A. W. (1.993) . Children's aggressive and socially unskilled playground behavior with peers: Origins in early family relations. In C. H. Hart (Ed.), Children on playgrounds: Research perspectives and applications (pp. 240-270). Albany: SUNY Press.

Porter, B., \& O'Leary, K. D. (1980). Marital discord and childhood behavior problems. Journal of Abnormal Child Psychology, 8, 287295.

Robinson, C. C., Mandleco, B., Olsen, S. F., \& Hart, C. H. (1995). Authoritative, authoritarian, and permissive parenting practices: Development of a new measure. Psychological Reports, 77, 819-830.

Russell, A., \& Russell, G. (1996). Positive parenting and boys' and girls' misbehavior during a home obscrvation. International .ournal of Behavioral Development, 19, 291-307.

Siqueland, L., Kendall, P. C., \& Steinberg, L. (1996). Anxiety in children: Family environments and family interaction. Journal of Clinical Child Psychology, 25, 225-237.

Received December 5, 1996

Revision received October 15, 1997

Accepted October 23, 1997 